\title{
(Re) Pensando violência de gênero e transfeminicídio como violação de Direitos Humanos
}

\author{
Ana Luiza Pante ${ }^{1}$ \\ Miria do Nascimento de Souza ${ }^{2}$ \\ Estêvão Rafael Fernandes 3 \\ Universidade Federal de Rondônia
}

Resumo: O presente trabalho visa problematizar uma abordagem estritamente jurídica para situações de violências de gênero. Para tanto, partiremos de um estudo de caso envolvendo um transfeminicídio e a busca da família pela solução jurídica de casos semelhantes. Em seguida, problematizaremos as legislações de direitos humanos aplicáveis ao caso no Brasil, os procedimentos estritamente legais e os eventuais instrumentos passíveis para a judicialização do caso apresentado. Finalmente, nossa perspectiva se dará no sentido de propor uma metodologia baseada em uma ruptura epistêmica, buscando ampliar as possibilidades postas pelo olhar jurídico positivado, desde o giro decolonial (Water Mignolo) e do queer caboclo (Estêvão Fernandes e Fabiano Gontijo).

Palavras-chave: gênero; transfeminicídio; Direitos Humanos.

\footnotetext{
${ }^{1}$ Mestranda do Programa de Pós-Graduação Stricto Sensu Mestrado Profissional Interdisciplinar em Direitos Humanos e Desenvolvimento da Justiça da Fundação Universidade Federal de Rondônia (UNIR).

${ }^{2}$ Mestranda do Programa de Pós-Graduação Stricto Sensu Mestrado Profissional Interdisciplinar em Direitos Humanos e Desenvolvimento da Justiça da Fundação Universidade Federal de Rondônia (UNIR).

3 Antropólogo. Professor do Departamento de Ciências Sociais da Universidade Federal de Rondônia (UNIR) e do Programa de Pós-Graduação em Antropologia Social da Universidade Federal do Mato Grosso (UFMT).
} 


\title{
(Re)Thinking gender-based violence and transfeminidice as a violation of Human Rights
}

\begin{abstract}
The present work aims to problematize a strictly legal approach to situations of gender violence. To do so, we will start with a case study involving a transfeminicide and the family's search for a legal solution to similar cases. Next, we will problematize the human rights legislation applicable to the case in Brazil, the strictly legal procedures and the possible instruments for the judicialization of the case presented. Finally, our perspective will be to propose a methodology based on an epistemology-other, seeking to expand the possibilities posed by the positivist legal view, from the decolonial turn (Water Mignolo) and the queer caboclo (Estêvão Fernandes and Fabiano Gontijo).
\end{abstract}

Keywords: gender; transfeminicide; Human Rights.

\section{(Re) Pensando la violencia de género y el transfeminicídio como una violación de los Derechos Humanos}

\begin{abstract}
Resumen: El presente trabajo pretende problematizar un enfoque estrictamente jurídico de las situaciones de violencia de género. Para ello, partiremos de un estudio de caso que involucra un transfeminicídio y la búsqueda de la familia de una solución legal para casos similares. Luego, problematizaremos la legislación de derechos humanos aplicable al caso en Brasil, los procedimientos estrictamente legales y los posibles instrumentos para la judicialización del caso presentado. Finalmente, nuestra perspectiva será la de proponer una metodología basada en una epistemología-otra, buscando ampliar las posibilidades planteadas por la visión jurídica positivista, a partir del giro decolonial (Water Mignolo) y del caboclo queer (Estêvão Fernandes y Fabiano Gontijo).
\end{abstract}

Palabras clave: género; transfeminicídio; Derechos Humanos. 
$\mathrm{O}$ que acontece quando uma sociedade conservadora e preconceituosa, como a nossa, com um ordenamento jurídico historicamente marcado por sistemas excludentes, encontra situações para as quais suas próprias estruturas (epistêmicas, sociais, históricas, de poder, de classe, de gênero etc.) não estão plenamente preparadas? Quando esse ordenamento, essencialmente pautado nas lógicas da colonialidade e na retórica da modernidade esbarram em sujeitos fluidos, fora dos limites e capacidades de classificações herméticas estoicas, "objetivas" e pragmáticas - como reza a boa cartilha da modernidade-colonialidade?

Temos, hegemonicamente, uma concepção de normalização das representações e práticas sociais funda[menta]das em uma visão sexual binária; sobressaindo-se, nessa visão, a representação de padrão específico cuja epítome são homens, brancos, cis e heterossexuais (MISKOLCI, 1988), localizados em áreas urbanas de núcleos metropolitanos. Nesse contexto, o não enquadramento nesses padrões reforça o aparato discursivo da exclusão e da invisibilidade de sujeitos cuja identidade de gênero e/ou performance sexual não se "encaixa" ou coaduna, necessariamente, com o papel socialmente esperado no âmbito dessa concepção normalizadora.

Merece, neste aporte, destacar-se que dois conceitos são frequentemente confundidos: a orientação sexual de um indivíduo e a identidade de gênero. O primeiro está relacionado ao desejo sexual de uma pessoa para outra, podendo ser considerada de acordo com esse desejo heterossexual, homossexual ou bissexual (SILVA et al., 2016). Já o segundo conceito se relaciona a outra situação volitiva, é o reconhecimento de si dentro ou fora do padrão de gênero estabelecido pela sociedade (MOTT, 2009).

De forma simples e didática4, ao analisarmos as possibilidades dentro da orientação sexual, isto é, dentro da compreensão de por quem sentimos atração emocional/afetiva/sexual, nos deparamos com as letras L, G, B, as quais referemse, respectivamente, a Lésbicas, Gays e Bissexuais. Em termos de identidade de gênero, chamamos de cisgênero, ou de "cis", às pessoas que se identificam com o gênero que lhes foi atribuído quando nasceram, em razão de sua genitália.

Teríamos, assim - e, novamente, de modo resumido e didático -, a denominação transgênero, incluindo pessoas as quais não se identificam/reconhecem com o gênero que lhes foi designado no nascimento. Ao nascerem com determinado órgão sexual, receberam um determinado rótulo que as definiam como homem ou mulher; todavia, essas pessoas não se adequam a essa imposição, tendo a necessidade de transicionar para algo que lhes seja mais adequado, seja outro gênero (sigla T, de transexual), uma combinação deles (sigla $\mathrm{Q}$, de queer) ou nenhum (agênero/gender neutral), além das pessoas intersexuais (I). Cada uma dessas "letras" diversa, complexa, heterogênea e heteróclitas.

Para melhor contextualização, segue abaixo um quadro realizado Neil Franco, contendo um breve resumo sobre o desenvolvimento do movimento homossexual brasileiro, bem como das alterações das siglas:

\footnotetext{
4 Temos consciência de como os próximos parágrafos são extremamente resumidos ao apresentarem a diversidade sexual, mas o fazemos dessa forma a fim de não nos deslocarmos demais de nosso objeto. Esperamos contar com a compreensão e indulgência das leitoras, leitores e leitorxs nesse sentido.
} 


\begin{tabular}{|c|l|}
\hline \multicolumn{3}{|c|}{ Quadro 14: Descrição resumida do Movimento Homossexual Brasileiro } \\
\hline Anos 60 & - Organização entre homossexuais masculinos para socialização. \\
\hline Anos 70 & $\begin{array}{l}\text { - Primeiras formas de organização política entre homossexuais masculinos. } \\
\text { - Criação do Movimento Homossexual Brasileiro (MHB). }\end{array}$ \\
\hline 1979 & - Grupo Somos anuncia sua existência em debate na USP. \\
\hline 1980 & - Criação do Grupo de Ação Lésbico-Feminista. \\
\hline $1980-1992$ & - Realização de seis ediços do Encontro Brasileiro de Homossexuais (EBHO). \\
\hline 1993 & $\begin{array}{l}\text { - Realizção do VII Encontro Brasileiro de Lésbicas e Homossexuais. } \\
\text { - Realização do I Encontro Nacional de Travestis. } \\
\text { - Criação do Festival de Cinema GLS (Gays, Lésbicas e Simpatizantes). }\end{array}$ \\
\hline 1995 & $\begin{array}{l}\text { - Realização do VIII Encontro Brasileiro de Gays e Lésbicas. } \\
\text { - Realização do I Encontro Brasileiro de Gays e Lésbicas que trabalham com AIDS. } \\
\text { - O movimento torna-se Movimento de Gays e Lésbicas (MGL). }\end{array}$ \\
\hline 1997 & $\begin{array}{l}\text { - Realização do IX Encontro Brasileiro de Gays, Lésbicas e Travestis. } \\
\text { - Realização do II Encontro Brasileiro de Gays e Lésbicas que trabalham com AIDS. }\end{array}$ \\
\hline 1998 & $\begin{array}{l}\text { - Adequando-se ao movimento internacional, adota-se a sigla GLBT (Gays, Lésbicas, } \\
\text { Bissexuais e Transgêneros - Travestis e Transexuais). }\end{array}$ \\
\hline 2008 & $\begin{array}{l}\text { - Realização da I Conferência Nacional de Políticas Públicas para GLBT. } \\
\text { - Mudança da sigla para LGBT (Lésbicas, Gays, Bissexuais, Travestis e Transexuais). }\end{array}$ \\
\hline
\end{tabular}

Fonte: FRANCO, 2009: 67

Como se vê, a sigla GLS (Gays, Lésbicas e Simpatizantes) foi substituída por GLBT (com a inclusão de Bissexuais e Transgêneros e exclusão dos Simpatizantes), e, posteriormente, também substituída por LGBT (Lésbicas, Gays, Bissexuais, Travestis, Transexuais e Transgêneros), com o objetivo de reconhecer a atuação e privilegiar as identidades lésbicas como uma forma de reparação ou de reconhecimento do processo histórico de invisibilidade pelo qual foram submetidas.

$\mathrm{Na}$ atualidade há inclusão de variações da sigla LGBT, para designar outros movimentos e identidades em construção, como a LGBTTTQQIAA com o intuito de incluir um maior número de elementos, ou ainda a sigla inglesa LGBTQQICAPF2K+ que procura uma maior abrangência. Para este trabalho optamos pela sigla LGBTIQA+ (Lésbicas, Gays, Bissexuais, Travestis, Transexuais, Transgêneros, Intersexos, Queer, Assexuais).

As pessoas LGBTIQA+ no Brasil sofrem, historicamente, um processo marcado por dispositivos e discursos religiosos, jurídicos e biomédicos os quais produziram materialidades cujos efeitos atuais resultam em sua acentuada subalternização, relegando-as a um elevado déficit de cidadania, marcado pela privação de direitos elementares que a toda população deveriam ser assegurados em um Estado Constitucional Democrático de Direito.

Os direitos sexuais estão correlacionados à orientação sexual ou identidade de gênero e, estes, inseridos nos princípios dos direitos humanos, em especial, a necessidade do indivíduo quanto à sua identidade. $\mathrm{O}$ direito à sexualidade não se restringe tão somente à reprodução, mas ao direito das pessoas quanto à forma de viverem, de expressarem seus gêneros, afetos e desejos perante a sociedade.

No tocante a esse universo do Direito e dos Direitos Humanos, Rios, por exemplo, aponta para uma questão fundamental: a necessidade de a sociedade se educar quanto aos princípios fundamentais, incluindo os direitos sexuais, pois a sociedade não apenas não foi educada a respeitar as diversidades, como ainda traz consigo os dogmas de uma lógica perversa do pecado, da imposição de um padrão de normalidade em um contexto conservador muitas vezes hipócrita e 
cadastrador de mudanças, o que se reflete nas atuações de legisladores, promotores, juízes e advogados (RIOS, 2007).

Com isso em mente, apresentamos a seguir um caso envolvendo um transfeminicídio (ficcional, desenvolvido enquanto "sujeito coletivo", a partir da bricolagem de dois casos concretos - feminicídio de repercussão nacional e um homicídio de pessoa trans não envolvendo a questão de gênero) ${ }^{5}$. A solução jurídica encontrada foi fruto de uma discussão para a disciplina de Jurisdição e Direitos Humanos ofertada no curso de Mestrado Profissional Interdisciplinar em Direitos Humanos e Desenvolvimento da Justiça, na qual se propôs uma pesquisa envolvendo os conceitos trabalhados.

\section{Simone: uma trajetória}

João e Maria procuraram a Associação dos Transexuais de Rondônia, denominada ANTRARO, a fim de encontrar uma estratégia de atuação para o caso de homicídio de sua filha Simone da Silva, popularmente conhecida como Simone. $\mathrm{O}$ caso foi designado às autoras deste texto e, nos próximos parágrafos, segue o relato dos pais - como dissemos, Simone existe enquanto várias Simones, às quais tivemos acesso enquanto pesquisadoras, ativistas e operadoras do Direito.

Simone da Silva, nascida do sexo masculino, com nome de registro de Samuel da Silva, 32 anos, moradora de Porto Velho, Rondônia, possuía ensino superior incompleto em Administração. Os pais de Simone informaram que ela sempre se sentiu rejeitada em virtude da dificuldade na compreensão, por parte de familiares e conhecidos, de sua identidade - sobretudo em um contexto tão conservador quanto o das periferias amazônicas.

Simone da Silva, mulher transafroameríndia, ribeirinha, cabocla, proveniente da região Norte do Brasil, nascida do sexo masculino, com nome de registro de Samuel da Silva, 32 anos, vinda de família de classe social média a baixa, moradora de Porto Velho, Rondônia, de características de raça/etnia parda, possuía ensino superior incompleto em Administração. Os pais de Simone informaram que ela sempre se sentiu rejeitada em virtude da dificuldade na compreensão, por parte de familiares e conhecidos, de sua identidade - sobretudo em um contexto tão conservador quanto o das periferias amazônicas.

Aos 20 anos, Simone iniciou o processo de transição de gênero, fazendo uso apenas de hormônios orais; não colocou prótese de silicone, nem realizou a cirurgia de redesignação sexual, por ter pavor de procedimentos invasivos.

Simone deixou de ser Samuel, aos olhos do Estado, apenas em 2018, após a decisão do Supremo Tribunal Federal, por meio da Ação Direta de Inconstitucionalidade (ADI) 4275. Só então ela conseguiu realizar a alteração do registro civil, sem realizar qualquer outro procedimento cirúrgico invasivo.

Ela teve inúmeros relacionamentos amorosos, nenhum deles considerados "saudáveis" por seus pais. O último relacionamento amoroso foi com César de Oliveira, então com 20 anos; conheceram-se na faculdade que ela frequentava e ficaram juntos por aproximadamente seis meses.

Certo dia, o casal teve um desentendimento por motivos desconhecidos, e a discussão levou a um registro de Boletim de Ocorrência: da ameaça à agressão e, daí ao assassinato, o caminho foi curto. Na mesma delegacia em que foi realizado o Boletim de Ocorrência de agressão a Simone, prosseguiu-se a investigação do crime praticado por César. O Delegado de plantão instaurou um inquérito, 
intimou os familiares e as testemunhas, solicitou e analisou os laudos de necropsia e de local da morte, enviados pela Polícia Científica.

$\mathrm{O}$ indiciado se apresentou na delegacia, foi devidamente interrogado e assumiu o crime. Explicou que, diante da condição do gênero de sua companheira, ele a via como representação do demônio e, por estar apaixonado por ela, só conseguiria se libertar se a matasse. Depois do assassinato, retirou o coração da vítima e o substituiu por uma imagem de santo.

\section{Os Direitos Humanos e o Direito de ser Humana no Direito: uma digressão}

Em um contexto no qual se advoga que "direitos humanos" sejam para "humanos direitos", até que ponto as normas alcançam a complexidade do drama social implicado no assassinato de Simone? Fizéssemos, aqui, uma "descrição densa" de Simone, a que conclusões chegaríamos em termos de seus Direitos e da aplicabilidade desta ou daquela norma a partir de sua trajetória? Com o perdão do (pobre) jogo de palavras, a pergunta é óbvia: à luz do Direito, conseguiríamos compreender direito todos os elementos por trás da morde de Simone? A norma, basta?

Para começar essa digressão, cumpre destacar que na introdução do livro "Se Deus fosse um ativista de direitos humanos" [Direitos Humanos: uma hegemonia frágil] vem a constatação de que "a hegemonia dos direitos humanos como linguagem de dignidade humana é hoje incontestável. No entanto, esta hegemonia convive com uma realidade perturbadora. A grande maioria da população mundial não é sujeito de direitos humanos. É objeto de discursos de direitos humanos" (SANTOS, 2014: 3).

Além da maior parte da humanidade não se ver inclusa nesse modelo de justiça, as ações estatais e de organizações internacionais em muitas situações de conflitos e violências, acabam por violar os direitos humanos aos quais dizem defendê-los. Os direitos humanos gozam de uma hegemonia social incontestável, mas são frágeis em sua tarefa básica de diminuir as desigualdades e garantir os direitos dos oprimidos no âmbito das sociedades (SANTOS, 2014).

Passamos agora a mencionar as normas de direitos humanos aplicadas à questão de gênero. Em um estudo realizado à luz das legislações internacionais na proteção de direitos humanos, percebeu-se a dimensão - simbólica, inclusive - da exclusão dos direitos dessas pessoas nos diplomas legais, apontando um déficit considerável e uma lógica legislativa à beira da discriminação (LELIS; GALIL, 2018).

Apesar de os instrumentos legislativos e jurídicos internacionais versarem a respeito da proteção universal dos direitos humanos - frisamos: igualdade entre os sexos, gêneros e sexualidade -, é necessário apontar documentos os quais foram específicos na proteção desses direitos (VITALE; NAGAMINE, 2018). Essa especificidade surge apenas na interpretação das normas internacionais de direitos humanos, visto que as disputas de direitos internacionais para as pessoas LGBTIQA+ são omissas ou pouco discutem a respeito da "orientação sexual" (NAGAMINE, 2019).

No contexto internacional, não há leis internacionais dedicadas a essas pessoas, especificamente, tampouco menção à orientação sexual ou à identidade de gênero. No entanto, apesar da ausência nominal da temática na ordem internacional, é notável a ampliação das discussões a respeito da orientação sexual e da identidade de gênero enquanto tema de direitos humanos - citamos a atuação da 
Corte Interamericana de Direitos Humanos e da Corte Europeia de Direitos Humanos (NAGAMINE, 2019).

Aliás, por um longo período, não houve qualquer publicação de documento oficial ou mesmo manifestação relacionada à temática de gênero, em especial a aspectos de igualdade de gênero, orientação sexual ou identidade de gênero. Tal fato ainda pode ser explicado pela baixa organização social ou de produção acadêmica até há relativamente pouco tempo (SILVA; BRABO; MACIEL, 2019).

Ainda assim, é possível analisar a aplicação de normas de direitos humanos na questão de gênero ao se interpretar extensivamente tais legislações. O primeiro caso é a Declaração Universal dos Direitos Humanos, que em seu artigo II.1 dispõe sobre a abrangência dos direitos, sem, no entanto, mencionar a questão de gênero ou sexual. Nesse mesmo instrumento legislativo, há outras passagens que podem ter aplicação por analogia, sendo elas: art. VII, ao tratar da vedação à discriminação e artigo XVI.1, menciona o direito ao casamento (Lelis; Galil, 2018).

No quesito legal, destaca-se, no Brasil, o Pacto Internacional de Direitos Econômicos, Sociais e Culturais (Pidesc), recepcionado pelo Decreto $n^{0} 591$, de 6 de julho de 1992. Nesse instrumento legal, alguns pontos se destacam pela vedação à discriminação, sem fazer menção aos direitos das pessoas LGBTIQA+; a exemplo pode-se citar o artigo $2^{\circ}$, item II, que dispõe sobre essa garantia diante de motivos como raça, cor, sexo, religião (BRASIL, 1992a).

O Pacto Internacional de Direitos Civis e Políticos (PIDCP), recepcionado pelo Decreto $\mathrm{n}^{0}$ 592, de 6 de julho de 1992, também pode ser utilizado de forma complementar à proteção das pessoas LGBTIQA+. Essa legislação possui, em seus artigos $2^{\circ}, 4^{\circ}, 24$ e 26, referência à proibição de distinção ou tratamento desigual a parâmetros como raça, cor, sexo, língua e, no artigo 23, reconhece o direito ao matrimônio e à formação de família a casais homoafetivos (LELIS; GALIL, 2018).

O Pacto de São José da Costa Rica, recepcionado no Brasil pelo Decreto $\mathrm{n}^{\mathrm{o}}$ 678 , de 6 de novembro de 1992, preceitua no mesmo caminho dos pactos anteriores (Pidesc e PIDCP). Há, no decreto $n^{0}$ 678/92, referência à não discriminação por motivos diversos, dentre eles a raça, cor, sexo, idioma, opiniões políticas ou qualquer outra natureza, bem como a proteção à família e ao casamento (Brasil, 1992b).

Os princípios de Yogyakarta também devem ser mencionados. Apesar de não fazerem parte de uma legislação interna brasileira, são um documento internacional que deverá ser utilizado como uma releitura de situações de discriminação ou estigma diante da questão de gênero. A ideia geral desses princípios recomenda que não há necessidade da emissão de textos internacionais ou nacionais de proteção de direitos a determinados grupos, mas a aplicação dos princípios gerais da lei internacional já existente (CORRÊA, 2012).

Os princípios de Yogyakarta tiveram seu lançamento no ano de 2007, em Genebra, em uma sessão do Conselho de Direitos Humanos (CDH) da Organização das Nações Unidas (ONU). Foram elaborados por 29 especialistas em direitos humanos naquela ocasião; e no ano de 2017 esses princípios foram ampliados, acrescentando-se a questão da interseccionalidade (LELIS; GALIL, 2018).

Por fim, mencionamos a Convenção Interamericana Contra Toda Forma de Discriminação e Intolerância, primeiro e único documento aprovado pela Assembleia Geral da Organização dos Estados Americanos (OEA), que possui vinculação à temática LGBTIQA+. Tal documento foi uma iniciativa brasileira e 
aprovado no ano de 2013, tendo ainda um caráter vinculante enquanto documento internacional (LELIS; GALIL, 2018).

Em vários trechos do texto da Convenção Interamericana Contra Toda Forma de Discriminação e Intolerância, há referência ao conceito de gênero; citamos o preâmbulo e o artigo 1, os quais consideraram discriminação aspectos relacionados a nacionalidade, orientação sexual, identidade e expressão de gênero, opinião política, deficiência, característica genética, entre outros aspectos (OEA, 2013).

Já no contexto especificamente brasileiro, diante de nossas legislações relacionadas a direitos humanos, bem como dos documentos que podem servir de base para decisões judiciais, torna-se essencial discutir o caminho procedimental para a aplicação prática em casos reais, como o caso de Simone.

Nesse aspecto, a ANTRARO, a associação que foi procurada pelos pais de Simone, está constituída há mais de um ano e, em sua atuação jurídica, identifica, analisa e produz pareceres e notas técnicas sobre legislações que afetam os direitos humanos; realiza ações de litigância estratégica, judicial e extrajudicial, no âmbito nacional e internacional; monitora decisões do sistema de justiça e produz pesquisas para sensibilização e advocacy, por meio de suas advogadas e advogados.

No caso de Simone, não se trata de homicídio comum, já contemplado pelas regras do art. 121 do Código Penal, com a qualificadora do meio cruel, mas sim de caso de grave violação de direitos humanos, tendo em vista que há uma falha reiterada/sistêmica do Estado Brasileiro na proteção de pessoas LGBTIQA+, que faz com que o Brasil figure como o país que mais mata a população trans no mundo. Destaca-se que Brasil, México e Estados Unidos, entre $1^{\circ}$ de janeiro de 2008 e 30 de setembro de 2020, são, nessa ordem, os três países com mais casos de assassinatos de pessoas trans reportados no mundo (BENEVIDES; NOGUEIRA, 2021).

Merece destaque o fato de que faltam dados estatísticos governamentais sobre a violência sofrida pela população LGBTIQA+, e que os dados quantificados no Brasil são realizados por setores da sociedade civil e de movimentos sociais. Isso, por si só, é significativo em relação à LGBTIQAfobia estrutural: ao mesmo tempo em que somos, sabida e reiteradamente, o país que mais mata a população trans no mundo, não temos dados oficiais mapeando/informando os assassinatos de pessoas trans nos Estados-membros (Benevides; Nogueira, 2021). O preconceito estatal e sistêmico se mostra na invisibilidade estrutural: o descaso torna-se política pública, sobretudo em tempos e contextos de ultraconservadorismos. A invisibilidade gera a falta de políticas públicas específicas (de segurança, inclusive) e vice-versa.

Apenas em 2020 que, pela primeira vez, a publicação do Anuário Brasileiro de Segurança Pública trouxe dados sobre violência contra a população LGBTIQA+. Mesmo com sua publicação, 15 estados e o Distrito Federal não possuem qualquer informação sobre violências motivadas por orientação sexual ou identidade de gênero - e daqueles que disponibilizaram dados (onze, no total) nenhum possui dados sobre assassinatos dessa população (BENEVIDES; NOGUEIRA, 2021).

Outro ponto que merece destaque é a realidade que Simone encontra-se inserida: uma transmulher na Amazônia. Diferentemente dos outros contextos regionais, as experiências de diversidade sexual bem como de gênero na Amazônia não possuem os mesmos modelos ou pautas dos grandes centros urbanos brasileiros, em especial do eixo centro-sul. São mundos reais e simbólicos com 
barreiras intransponíveis de forma a distinguir, consideravelmente, as interações entre as pessoas (GONTIJO; ERICK, 2017).

De forma complementar e assustadora, Rondônia, estado da região Norte, é considerado conservador tanto em termos políticos quanto em termos morais, o que em termos gerais pode contribuir para o aumento das discriminações, segregação das pessoas trans e violações de determinados direitos. É notório a invisibilização, estigmatização e até mesmo marginalização das pessoas trans no território rondoniense diante da falta de acolhimento no tratamento a esse grupo populacional, desde os postos de saúde até as delegacias (SILVA; SCHMID, 2020).

Desse modo, não restam dúvidas sobre a falha estrutural do Estado Brasileiro com relação à identificação, apuração e tipificação dos delitos de ódio envolvendo as pessoas LGBTIQA+. Em outras palavras, fica claro que o Estado fracassou e fracassa, sistêmica e sistematicamente, em dispor de meios eficazes para proteger, respeitar e dar efetividade aos direitos LGBTIQA+. Contudo, esse aspecto de sistematicidade - não pode ser tratado como algo dado. A invisibilidade estrutural em relação a violências - cotidianas, inclusive - impostas sobre essas pessoas não se dá em um vazio de relações de poder, tampouco fora de relações historicamente construídas. O vácuo institucional nos mecanismos de defesa desses atos nos expõem, também, a gênese na própria noção de Direito, enquanto parte constitutiva do aparato discursivo, burocrático, moral e mental moderno, ocidental que se retroalimenta em termos da constituição de sua própria legitimidade.

\section{Algumas considerações finais}

Simone, enquanto tipo ideal, retrata a realidade da maioria das pessoas trans no Brasil, justamente por evidenciar as franjas de um sistema voltado para a manutenção da heteronormatividade, da masculinidade e de um sistema moral tradicionalista patriarcal, repressivo e misógino. Reflexo disso é a relativa baixa produção legislativa internacional de direitos humanos relacionados à questão de gênero e a ausência de normativas nacionais que envolvam a temática, de forma ampla. Mas o problema é mais profundo e, ao mesmo tempo, causa e efeito de uma nuvem discursiva excludente. Dito de forma clara, não há como pensar uma ordem fora das estruturas normalizadoras nos termos constituídos pela própria estrutura normalizadora. Propõe-se aqui, então dois movimentos concomitantes em termos de análise.

Em primeiro lugar, realizar o que o pensamento decolonial chama de "ruptura epistêmica" (cf. MIGNOLO, 2008): uma forma de agir/pensar/ser fora das opções impostas, historicamente, pela lógica da colonialidade e pela retórica da modernidade. O Direito é, de várias formas, o instrumento privilegiado por meio do qual essa ordem se mantém e se reproduz. O Estado, como o conhecemos, não é possível fora de um sistema legal que o sustente e, claro, de um aparato normatizador que o ampare: e as lógicas dentro das quais esses mecanismos operam, estrutural e historicamente, são no sentido de uma continuidade. Mais do que mera crítica ao Direito, desde um olhar decolonial, nossa intenção aqui é salientar não exatamente os instrumentos visíveis dessa estrutura, mas, sobretudo, os aspectos epistemológicos, morais e políticos que a sustentam.

Em segundo lugar, propõe-se aqui um movimento crítico e crísico diante desses aspectos, conjugando uma perspectiva não apenas anticolonial (posto que um contraponto epistêmico radical) mas, também, antinormalizadora - e, portanto, queer. Entretanto, tal viés não se dá, novamente, em um limbo socio-histórico, mas em um contexto de ultraconservadorismo na periferia amazônica, com 
elementos não apenas de violência e preconceito extremados, mas, também, a partir de uma cultura religiosa, trajetórias pessoais e ethos bem peculiares de uma região específica da Amazônia. Levar isso em conta é fundamental para se desvelar outras camadas pelas quais passam esse tipo de fenômeno. Trata-se, aqui, de contrapor justamente essas estruturas normalizadoras de forma radical, indo ao encontro de um queer caboclo (FERNANDES; GONTIJO, 2017) que contraponha perspectivas metropolitanas, urbanas, ocidentais e centro-sulistas. Um queer radical no sentido de trazer à tona não apenas os aspectos formais desses atos de violências (sobretudo a invisibilidade) mas, também, a rede de relações morais e religiosas sobre as quais agentes públicos, operadores do Direito, testemunhas etc., sustentam suas ações e justificam suas eventuais inércias.

Sua falta de ação é "a" ação esperada dentro dos mecanismos pelos quais a colonialidade/modernidade/cisheteronormatividade age, de modo intrínseco à própria noção de Estado e à perspectiva de Poder que lhe é inerente. $\mathrm{O}$ desafio posto é, portanto, não apenas o de transcender esse sistema normativo mas, sobretudo, escancarar as feridas coloniais por ele mantidas - não somente como movimento de resistência mas, de modo premente, como estratégia de sobrevivência.

Recebido em 4 de março de 2021. Aprovado em 28 de abril de 2021. 


\section{Referências}

BENEVIDES, B. G.; NOGUEIRA, S. N. B. Dossiê assassinatos e violência contra travestis e transexuais brasileiras em 2020. São Paulo: [s.n.]. Disponível em: $<$ 15/02/2021https://antrabrasil.files.wordpress.com/2021/01/dossie-trans2021-29jan2021.pdf $>$. Acesso em: 15 fev. 2021.

BRASIL. "Decreto no 591, de 6 de julho de 1992". Atos Internacionais. acto Internacional sobre Direitos Econômicos, Sociais e Culturais, 1992a. Disponível em: <http://www.planalto.gov.br/ccivil_03/decreto/1990-1994/Do591.htm>. Acesso em: 16 fev. 2021

BRASIL. "Decreto no 678, de 6 de novembro de 1992". Convenção Americana sobre Direitos Humanos (Pacto de São José da Costa Rica), de 22 de novembro de 1969., 1992b. Disponível em: <http://www.planalto.gov.br/ccivil_03/decreto/Do678.htm>. Acesso em: 16 fev. 2021.

CORREAA, S. O percurso dos direitos sexuais: entre margens e centros. Bagoas Estudos gays: gêneros e sexualidades, 3 (4), 2012.

FRANCO, N. A diversidade entra na escola: Histórias de professores e professoras que transitam pelas fronteiras das sexualidades e do gênero. [s.l: s.n.].

GONTIJO, F.; ERICK, I. Experiências da Diversidade Sexual e de Gênero e Sociabilidades na Amazônia: convite para se pensar as relações sociais como atos históricos singulares. Aceno, 4 (7): 249-272, 2017.

LELIS, R. C.; GALIL, G. C. "Direito Internacional Monocromático: previsão e aplicação dos direitos LGBTI na ordem internacional". Revista de Direito Internacional, 15 (1): 277-298, 2018.

MISKOLCI, R. A teoria queer e a questão das diferenças: por uma analítica da normatização. Edição do autor (mimeo), 2004. pp. 1-19.

MOTT, L. R. O/a jovem homossexual na escola: Noções básicas de direitos humanos para professores. Edição do autor (mimeo), 2009.

NAGAMINE, R. R. V. K. "Os direitos de pessoas LGBT na ONU (2000-2016)". Sexualidad, Salud y Sociedad, 31 (1): 28-56, 2019.

OEA, O. DOS E. A. Convenção Interamericana contra toda forma de discriminação e intolerância. [s.l: s.n.].

RIOS, R. R. Homossexualidade e Direitos Sexuais - Reflexões a partir da decisão do STF. Porto Alegre: [s/d.].

SANTOS, B. DE S. Se Deus fosse um ativista dos Direitos Humanos. São Paulo: 1 ed., 2014.

SILVA, M. E. F. DA; BRABO, T. S. A. M.; MACIEL, T. S. Direitos Humanos das mulheres e das pessoas LGBT: a relação agridoce entre gênero e educação em meio a desafios contemporâneos. Interfaces Científicas, 7 (1): 157-168, 2019.

SILVA, G. W. D. S. et al. Situações de violência contra travestis e transexuais em um município do nordeste brasileiro. Revista gaúcha de enfermagem, 37 (2): e56407, 2016.

SILVA, L. M.; SCHMID, B. B. "Francinny, Úrsula e Welly: mulheres trans-negras universitárias em Rondônia - experiências de opressão e resistência". In: 
Caminhos possíveis à inclusão V: Gêneros, (trans)gêneros e educação - alguns enfrentamentos. Curitiba: Brazil Publishing, 2020.

VITALE, D.; NAGAMINE, R. R. V. K. Gênero, direito e relações internacionais: debates de um campo em construção. Salvador: Edufba, 2018.

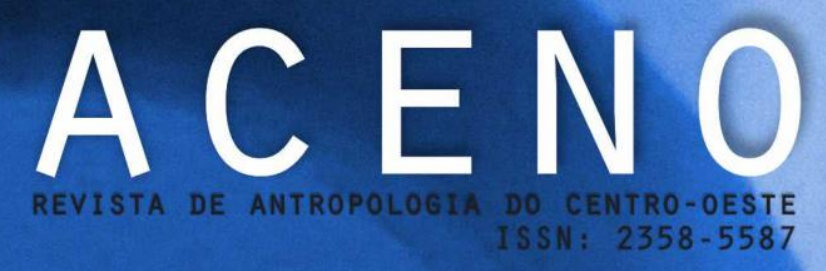

A Aceno recebe em FLUXO CONTÍNUO, artigos livres, resenhas, ensaios fotográficos, dossiês (propostas). Interessados em atuar como pareceristas podem realizar seus cadastros no site 